DOI: $10.5800 /$ GT-2021-12-3-0544

\title{
COMMENTS ON THE ARTICLE AUTHORED BY M.V. MINTS AND K.A. DOKUKINA - THE BELOMORIAN ECLOGITE PROVINCE (EASTERN FENNOSCANDIAN SHIELD, RUSSIA): MESO-NEOARCHEAN OR LATE PALEOPROTEROZOIC?
}

\author{
S.G. Skublov $\circledast^{1,2 \otimes}$, A.V. Berezin $\overbrace{}^{1,3}$, L.I. Salimgaraeva $\left(^{1,2}\right.$
}

${ }^{1}$ Institute of Precambrian Geology and Geochronology RAS, 2 Makarov Emb, Saint Petersburg 199034, Russia

${ }^{2}$ Saint Petersburg Mining University, 2, 21st Line, Saint Petersburg 199106, Russia

${ }^{3}$ Saint Petersburg University, 7/9 Universitetskaya Emb, Saint Petersburg 199034, Russia

\begin{abstract}
The comments are given on the article authored by M.V. Mints and K.A. Dokukina - The Belomorian Eclogite Province (Eastern Fennoscandian Shield, Russia): Meso-Neoarchean or Late Paleoproterozoic? (Geodynamics \& Tectonophysics 2020, 11 (1), 151-200). The Belomorian (White Sea) province of the Fennoscandia Shield is a key site for studying the tectonics of the early periods because numerous Precambrian eclogites have been found there. It was not anticipated, but the problem of age determinations of the eclogite metamorphism of gabbroids in the White Sea mobile belt has turned out to be extremely relevant not only for this region, but also for the Precambrian geology in general. The reason is that a number of authors determine the age of eclogites as Archean (2.7-2.8 Ga), which makes the White Sea mobile belt the only example of the Archean eclogite metamorphism in the world and, therefore, the only dated evidence in support of the plate tectonic model of the evolution of the Earth's crust at the earliest stage of its formation. The article consistently provides a critical analysis of the arguments put forward by the supporters of the Archean age of the eclogites of the White Sea mobile belt. Special emphasis is made on the isotope geochronological and geochemical features of the composition of zircons from eclogite samples, as well as on the phase and chemical compositions and distribution patterns of mineral inclusions. Considering the age of eclogite metamorphism that led to the formation of eclogites in the White Sea mobile belt, we propose our interpretation based on a set of independent isotope geochemical dating methods, including the local $\mathrm{U}-\mathrm{Pb}$ method for heterogeneous zircons with magmatic cores and eclogite rims, the Lu-Hf and Sm-Nd methods for the minerals of eclogite paragenesis (garnet and omphacite). And this age interpretation is fundamentally different from the one described in the commented article: all the three methods independently determine the eclogite metamorphism as Paleoproterozoic and yield the same age of circa $1.9 \mathrm{Ga}$. According to our data, the eclogites of the White Sea mobile belt are among the most ancient high-pressure rocks, their reliably established age of metamorphism is circa $1.9 \mathrm{Ga}$, and the age of the magmatic protolith is the range of 2.2-2.9 Ga.
\end{abstract}

KEY WORDS: eclogite; Precambrian; White Sea mobile belt; petrochronology; isotope age; zircon; U-Pb method; Sm-Nd method; Lu-Hf method

FUNDING: The publication was prepared under the research project of the Institute of Precambrian Geology and Geochronology RAS and supported by the Russian Foundation for Basic Research (Grant 20-35-90001).

\section{COMMENT}

Correspondence: Sergey G. Skublov, skublov@yandex.ru
Received: July 28, 2020

Revised: September 29, 2020

Accepted: October 14, 2020

FOR CITATION: Skublov S.G., Berezin A.V., Salimgaraeva L.I., 2021. Comments on the article authored by M.V. Mints and K.A. Dokukina The Belomorian eclogite province (Eastern Fennoscandian shield, Russia): Meso-Neoarchean or Late Paleoproterozoic? Geodynamics \& Tectonophysics 12 (3), 652-661. doi:10.5800/GT-2021-12-3-0544 


\title{
КОММЕНТАРИИ К СТАТЬЕ М.В. МИНЦА И К.А. ДОКУКИНОЙ «СУБДУКЦИОННЫЕ ЭКЛОГИТЫ БЕЛОМОРСКОЙ ЭКЛОГИТОВОЙ ПРОВИНЦИИ (ВОСТОК ФЕННОСКАНДИНАВСКОГО ЩИТА, РОССИЯ): МЕЗОАРХЕЙ, НЕОАРХЕЙ ИЛИ ПОЗДНИЙ ПАЛЕОПРОТЕРОЗОЙ?»
}

\author{
С.Г. Скублов ${ }^{1,2}$, А.В. Березин ${ }^{1,3}$, Л.И. Салимгараева ${ }^{1,2}$
}

\author{
${ }^{1}$ Институт геологии и геохронологии докембрия РАН, 199034, Санкт-Петербург, наб. Макарова, 2, Россия \\ ${ }^{2}$ Санкт-Петербургский горный университет, 199106, Санкт-Петербург, 21 линия, 2, Россия \\ ${ }^{3}$ Санкт-Петербургский государственный университет, 199034, Санкт-Петербург, наб. Университетская, 7/9, \\ Россия
}

АННОТАЦИЯ. Работа представляет собой критические комментарии к статье М.В. Минца и К.А. Докукиной «Субдукционные эклогиты Беломорской эклогитовой провинции (восток Фенноскандинавского щита, Россия): мезоархей, неоархей или поздний палеопротерозой?» (Geodynamics \& Tectonophysics. 2020. 11 (1), 151-200). Беломорская провинция Фенноскандинавского щита - ключевой пункт в исследованиях ранней тектоники, поскольку с ней связаны многочисленные находки докембрийских эклогитов. Проблема возраста эклогитового метаморфизма габброидов Беломорского подвижного пояса неожиданно оказалась крайне актуальной не только для геологии данного региона, но и для докембрийской геологии в целом, поскольку определения рядом авторов возраста эклогитов как архейского (2.7-2.8 млрд лет) делают Беломорский подвижный пояс единственным в мире примером архейского эклогитового метаморфизма и, следовательно, единственным продатированным свидетельством в пользу плейт-тектонической модели эволюции земной коры на самом раннем этапе ее становления.

В статье последовательно проведен критический разбор аргументов, выдвигаемых сторонниками архейского возраста эклогитов Беломорского подвижного пояса. Специальный акцент в работе сделан на изотопногеохронологических и геохимических особенностях состава циркона из эклогитов, а также на особенностях фазового и химического состава и характера распределения минеральных включений. Авторская трактовка возраста эклогитового метаморфизма, приведшего к образованию эклогитов Беломорского подвижного пояса, основанная на комплексе независимых изотопно-геохимических методов датирования - локальном U-Pb методе по гетерогенным цирконам с магматическими ядрами и эклогитовыми каймами, Lu-Hf и Sm-Nd методах по минералам эклогитового парагенезиса - гранату и омфациту, принципиально другая, чем в рассматриваемой статье: все три метода независимо друг от друга определяют эклогитовый метаморфизм как палеопротерозойский, с одним и тем же значением возраста - около 1.9 млрд лет. По нашим данным, эклогиты Беломорского подвижного пояса являются одними из самых древних высокобарических пород с достоверно установленным возрастом метаморфизма около 1.9 млрд лет при различном возрасте магматического протолита в интервале от 2.2 до 2.9 млрд лет.

КЛЮЧЕВЫЕ СЛОВА: эклогиты; докембрий; Беломорский подвижный пояс; петрохронология; изотопный возраст; циркон; U-Pb метод; Sm-Nd метод; Lu-Hf метод

ФИНАНСИРОВАНИЕ: Публикация подготовлена в рамках темы НИР ИГГД РАН при поддержке гранта РФФИ 20-35-90001.

\section{1. ВВЕДЕНИЕ}

Беломорская провинция Фенноскандинавского щита - ключевой пункт в исследованиях ранней тектоники, поскольку с ней связаны многочисленные находки докембрийских эклогитов. Проблема возраста эклогитового метаморфизма габброидов Беломорского подвижного пояса (БПП) неожиданно оказалась крайне актуальной не только для гелогии данного региона, но и для докембрийской геологии в целом, потому что при датировании эклогитизированных габброидов Беломорья U-Pb методом по циркону некоторые исследователи пришли к выводу о том, что возраст метаморфизма эклогитов находится в интервале 2700-2800 млн лет (например [Dokukina et al., 2010, 2012, 2014; Dokukina,
Konilov, 2011; Shchipansky et al., 2012; Dokukina, Mints, 2019]). До сих пор ни в одном регионе мира архейские эклогиты не были обнаружены - считается вследствие небольшой мощности земной коры в архее - и потому определения возраста 2.7-2.8 млрд лет делают БПП единственным в мире примером архейского эклогитового метаморфизма и, следовательно, единственным продатированным свидетельством в пользу плейт-тектонической модели эволюции земной коры на самом раннем этапе ее становления. К сожалению, выводы об архейском возрасте эклогитов БПП не были подкреплены должным образом исследованием геохимии циркона, a результаты U-Pb датирования циркона зачастую интерпретируются весьма вольно. Вышесказанное прежде 
всего имеет отношение к проявлениям эклогитов на двух опорных участках в пределах БПП - в районах Салмы и Гридино.

В рассматриваемой статье М.В. Минца и К.А. Докукиной проведено критическое обсуждение конкурирующих моделей и возраста (мезонеоархей или поздний палеопротерозой) для эклогитов района Салмы в БПП [Mints, Dokukina, 2020]. Специальный акцент в работе сделан на изотопно-геохронологических и геохимических особенностях состава циркона из эклогитов, а также на особенностях фазового и химического состава и характера распределения минеральных включений. Ниже будет проведен критический анализ спорных или некорректных, на наш взгляд, положений в статье М.В. Минца и К.А. Докукиной.

\section{2. МИНЕРАЛЬНЫЕ ВКЛЮЧЕНИЯ В ЭКЛОГИТАХ}

Начнем разбор этой работы с результатов работ авторов по исследованию минеральных включений, поскольку во многом именно на основе минеральных включений ими сделаны выводы о последовательности и параметрах метаморфических событий.

На с. 159 авторы приводят информацию, что «в порфиробласте граната обнажено включение клинопироксена, содержащего, в свою очередь, хлорит; встречены включения клинопироксена, который, помимо хлорита, включает и зерна идиоморфного граната». На основе подобных наблюдений делаются выводы о последовательной кристаллизации реликтовых минеральных парагенезисов, представленных на рис. 8. На данном рисунке, к сожалению, не указано, в каком месте «атоллового» граната произведен анализ. Следовательно, можно предположить два варианта: что гранат, моноклинный пироксен и хлорит формировались равновесно (что сразу ставит под сомнение вариант достижения эклогитовых РТ-условий) и что приведенная ассоциация - с пумпеллеитом - вполне могла формироваться на регрессивной ветви метаморфизма.

Рисунок 5, приведенный на с. 160, иллюстрирует «пиллоу-лавы» как свидетельство доэклогитовой истории пород, однако не рассматривается вариант их позднего формирования в зоне дробления габброидов с синхронной переработкой флюидами. Здесь же говорится, что «...в эклогитах - меланократовых метагаббро-норитах в нескольких позициях внутри хромистой шпинели обнаружены включения $\mathrm{Cr}$-содержащего диаспора... Присутствие диаспора свидетельствует, что породы... начинают этот путь непосредственно с поверхности океанского острова. В том же образце был обнаружен сапонит (смектит) (рис. 9). Сапонит также обычен в породах морского дна...». Описанное присутствие диаспора внутри хромистой шпинели весьма примечательно, однако вызывает некоторое недоумение. Во-первых, речь идет о габбро-норитах, т.е. полнокристаллических породах, которые никак не могли быть на «...поверхности океанского острова...». Во-вторых, диаспор - это водосодержащий минерал, типичный для глиноземистых пород. Его присутствие в виде включения в хромистой шпинели требует как минимум смены «водной» обстановки на «сухую» в течение крайне малого промежутка времени с повышением температуры от примерно $500{ }^{\circ} \mathrm{C}$ (для 15 кбар) до более $800{ }^{\circ} \mathrm{C}$ через область стабильности корунда, что при данном составе габбро-норитов и незначительной величине активности воды крайне маловероятно.

На с. 161 на рис. 7 профиль анализа граната не проходит через ту область, где установлены пумпеллеит, альбит и другие низкотемпературные фазы. Кроме того, атолловые гранаты характеризуются весьма частой негомогенностью - геометрический центр не всегда является таковым для рассматриваемого сечения зерна. Авторская интерпретация граната как «атоллового» интересна, но приведенный профиль его состава не имеет некоторых особенностей, типичных для прогрессивной ветви метаморфизма. Так, на контактах с матриксом и с серповидным пумпеллеитсодержащим агрегатом железистость граната (альмандиновый компонент) повышается, что можно интерпретировать как снижение температуры метаморфизма.

На с. 162 на рис. 8 представлено «...свидетельство последовательных стадий доэклогитового метаморфизма в обстановках спредингового хребта, океанского дна и зоны субдукции. Включения доэклогитовых минералов в лагуне атоллового граната из симплектитового эклогита...». Ассоциация пумпеллеита, хлорита, титанита, актинолита и роговой обманки в виде включений в гранате, в случае ее равновесности, стабильна при Т не выше $390{ }^{\circ} \mathrm{C}$ и P 8 кбар по реакции $\mathrm{Pmp} \rightarrow \mathrm{cZo+}$ $+\mathrm{Grs}+\mathrm{Chl}+\mathrm{Qz}+\mathrm{H}_{2} \mathrm{O}$ [Schiffman, Liou, 1980]. Как видно на фотографии, клиноцоизит в ассоциации отсутствует, а высокая железистость граната совместно с магнезиальной роговой обманкой ставит под сомнение проградный характер реакций. Кроме того, составы граната, плагиоклаза и роговой обманки, приведенные в таблице 19.1 первоисточника [Konilov et al., 2011], не позволяют оценить условия начала захвата «включения» гранатом из-за неравновесности фаз; приближенные оценки методом мультиравновесной термобарометрии TWQ [Berman, 1988] по Hbl+Pl минеральной паре coставляют около $400{ }^{\circ} \mathrm{C}$ и 3 кбар, что вполне согласуется с нашими доводами, приведенными выше. Следовательно, «...свидетельство последовательных стадий доэклогитового метаморфизма...» не подтверждено достаточно убедительно.

На с. 162 на рис. 9 изображено «...прорастание сапонита и шпинели в окружении низко-Al роговой обманки...». На изображении в проходящем свете отчетливо видны зеленые (шпинель - герцинит) и бурые зерна сапонит (по интерпретации авторов комментируемой статьи - «срастание»). Согласно первоисточнику данных [Konilov et al., 2011] - таблице 19.3, приведенный анализ шпинели действительно вполне соответствует ее петрографическому определению. Однако высокий рельеф и характер спайности у «бурой» фазы идентичен таковым у шпинели. Общеизвестно, что показатель преломления шпинелей такого состава достигает 
1.7-1.8, у сапонита (группа смектита) - 1.5-1.6. Твердость (оптически выражающаяся в рельефе) у этих фаз отличается еще больше - 7.5-8.0 у шпинели и 1.5-2.0 у сапонита. Исходя из этих параметров, можно предположить, что срастание «сапонита» со шпинелью есть не что иное, как зерна шпинели с разным составом (ряд герцинит - плеонаст). К сожалению, отсутствие изображений с введенным анализатором и местоположения точек микроанализа не позволяют однозначно убедиться в корректности идентификации вышеописанных фаз. Следует отметить и термодинамически проблематичное сонахождение шпинели и сапонита. Здесь же, на рис. 9, б, мы видим «...обрастание сапонита керолитом...» как пример «...доэклогитового метаморфизма...», но гораздо проще интерпретировать данное соотношение как процесс замещения ромбического (магматического) пироксена сапонитом, а затем и керолитом. Такие процессы неоднократно описаны при регрессивных изменениях основных пород. Кроме того, маловероятно, что такие фазы с ОН-группами, как диаспор, сапонит и керолит, остались «свежими» при последующих эклогитовых и гранулитовых метаморфизмах (интерпретация последовательности событий авторами рассматриваемой статьи), хотя их ассоциация с амфиболом говорит об обратном.

\section{3. ВКЛЮЧЕНИЯ В ЦИРКОНЕ}

На с. 163 характеристика микровключений в цирконе дана на основе известных публикаций [Kaulina et al., 2010; Li et al., 2017, 2018]. При этом все приведенные минералы не характеризуют условия эклогитовой фации - они, напротив, свидетельствуют о насыщении системы водой и углекислотой, а также REE (присутствие обогащенного REE минерала группы эпидота алланита). Последнее находит логическое объяснение, так как палеопротерозойские пегматиты, секущие эклогиты (например, известный карьер Куру-Ваара), весьма насыщены алланитом (кристаллы последнего достигают 1 м в длину). Таким образом, версия [Li et al., $2017,2018]$ о захвате отмеченных минералов в процессе роста циркона при участии флюидов кажется более правдоподобной.

На с. 167, приводя интерпретацию магматических ядер циркона с возрастом около 2.9 млрд лет, авторы указывают на наличие включений, отвечающих параметрам пренит-пумпеллиитовой фации метаморфизма, оценивая значения температуры в $850^{\circ} \mathrm{C}$. Остается неясной причина стабильности водосодержащих фаз при такой значительной температуре и крайне малой активности воды.

На с. 168 приводятся значения возраста по цирконам с геолого-геодинамической интерпретацией. Приведенная авторами интерпретация возраста кристаллизации магматических ядер циркона вполне однозначна (2.90-2.82 млрд лет). Возраст для «эклогитового» этапа (Т около $750{ }^{\circ} \mathrm{C}$, Р около 15 кбар) оценен в 2.83-2.78 млрд лет, временные рамки «гранулитового» этапа $\left(\mathrm{T} \leq 860^{\circ} \mathrm{C}\right)-$ как 2.78-2.73 млрд лет. Последний зафиксирован лишь по морфологии зерен циркона. Учитывая изложенные в статье свидетельства авторов о «доэклогитовой» метаморфической истории пород в условиях пренитпумпеллиитовой фации (не выше $390{ }^{\circ} \mathrm{C}$ и 8 кбар по [Schiffman, Liou, 1980]), следует предположить крайне быстрое изменение РТ-условий, никак не обсуждаемое авторами.

На с. 184 авторы также указыват на присутствие в цирконе расплавных включений (по [Li et al., 2017]) с интерпретацией «...Минеральные реакции, предшествовавшие пиковым РТ-параметрам, протекают в субсолидусном состоянии...РТ-траектория пересекает линию «влажного» солидуса уже в поле эклогитовой фации...». В качестве доказательства приводится утверждение, что «...участие парциального расплава в минеральных реакциях подтверждается наличием расплавных включений (в цирконе - авт.)...». Таким образом, расплавные включения являются свидетелями эклогитовой фации с частичным плавлением. В первоисточнике (c. 277, табл. 6 в [Li et al., 2017]) для образца эклогитов UzS-2 включения установлены как в ядре, так и в кайме, а в образце UzS-5 - только в ядре циркона. Как видно из данных анализа, составы включений пересыщены $\mathrm{SiO}_{2}$ и могут быть представлены как компоненты системы Qz-Ab-An. В ядре циркона расплавные включения обогащены натрием (около 5-6 мас. \% $\mathrm{Na}_{2} \mathrm{O}$ ) относительно включений в каймах зерен (около 1-2 мас. \% $\mathrm{Na}_{2} 0$ ). Отличительной характеристикой состава стекла в кайме циркона также является незначительное количество $\mathrm{K}_{2} \mathrm{O}$ (около 3 мас. \%). Предварительные оценки по простым системам Na-силикатных стекол [Sanditov, 2016; Zanotto, Cassar, 2017] позволяют ограничить температуру «стеклования» сверху в 810-820 으, а нижний предел «стеклования» расплавов (по [Mills, 2011]) составляет $675-645^{\circ} \mathrm{C}$.

Авторы утверждают, что рассмотренные выше расплавные включения в цирконах - «свидетели» эклогитовой фации. Этому утверждению противоречит наличие включений альбита и кварца с расплавными включениями похожего состава при отсутствии жадеита. Последнее может означать, что условия их равновесия были в области солидуса системы Qz-Ab-An $\left(+\mathrm{H}_{2} \mathrm{O}\right)$, в поле стабильности альбита, определяемой реакцией $\mathrm{Ab}=\mathrm{Jd}+\mathrm{Qz}$. Столь «кислые» составы стекол имеют значительную вязкость (lgh 8 по [Mills, 2011]) и крайне насыщены водой (до 6 мас. \% по [Holtz et al., 2001]), что может достигаться при давлении не выше 3-8 кбар [Silver, Stolper, 1985].

Рассматривая изложенные выше особенности расплавных включений в генетическом аспекте, можно предположить, что формировались они в интервале температур 650-800 드 и при давлении в пределах 3-8 кбар. Учитывая, что для сохранности расплавных включений необходимо относительно быстрое переохлаждение расплава, можно с большой долей уверенности утверждать, что при проградном сценарии эволюции пород, предполагаемом авторами статьи, это невозможно. Здесь стоит снова обратить внимание на отсутствие 
реакционных кайм и раскристаллизации у расплавных и минеральных включений, которые непременно должны присутствовать, так как на эклогиты накладывался, согласно авторам рассматриваемой статьи, архейский гранулитовый и палеопротерозойский гранулитовый и амфиболитовый этапы метаморфизма.

По нашему мнению, расплавные включения не являются однозначным свидетельством присутствия расплава на эклогитовом этапе архейского возраста. Одним из наиболее вероятных вариантов их генезиса является (по [Li et al., 2017]) проникновение по микротрещинам щелочного флюида, инициируемого пегматитами, возраст которых определен как палеопротерозойский (около 1840 млн лет [Skublov et al., 2010, 2011]).

\section{4. ОБОСНОВАНИЕ ВОЗРАСТА ЭКЛОГИТОВ}

Переходя собственно к обоснованию авторами статьи архейского возраста эклогитов, следует особенно отметить первую фразу авторов в этом разделе, что «собственно эклогитовые цирконы в эклогитах Салмы не были обнаружены» (с. 183), т.е. эклогиты есть, а цирконов, отвечающих высокобарическому метаморфизму, полностью преобразовавшему облик протолита, в них нет (!). Для коровых эклогитов из всех регионов Земли, датированию которых посвящены сотни публикаций, такая ситуация отмечена впервые. Тогда это какая-то уникальная особенность салминских эклогитов, или проблема все-таки заключается в авторской интерпретации результатов датирования эклогитов БПП, которое массово выполнялось как нами (авторами настоящих комментариев), так и нашими оппонентами, поддерживающими точку зрения об архейском возрасте эклогитового метаморфизма в БПП. На основании каких данных авторами комментируемой статьи был сделан вывод об архейском возрасте салминских эклогитов? В следующем предложении авторы отвечают на этот вопрос - «Результаты U-Pb и $\mathrm{Lu}-\mathrm{Hf}$ датирования цирконов из эклогитов и из секущей жилы плагиогранитного состава дали основание для заключения, что океаническая кора была субдуцирована и подверглась эклогитовому метаморфизму между 2.87 и 2.82 млрд лет».

Прежде чем прокомментировать это утверждение, отметим, что «секущая жила» (в ранних работах авторов она названа «адакитовой жилой» [Rosen et al., 2008; Mints et al., 2010]), по нашим данным, не сечет эклогиты. Это сегрегация лейкократового материала, своего рода «выплавка» - результат частичного плавления эклогитов, не выходящая за пределы тела эклогитов. Время ее образования в равной степени могло предшествовать эклогитовому метаморфизму или быть с ним одновременным.

\section{5. Нf-ИЗОТОПНАЯ СИСТЕМА}

Начнем с того, что Lu-Hf (метода) датирования циркона, на который ссылаются авторы комментируемой статьи, нет. Есть исследование изотопной системы Hf в цирконах как основном минерале-концентраторе этого элемента (т.н. Hf-систематика), которое позволяет рассчитать модельный возраст для магматической популяции циркона - это время отделения от мантийного источника расплава, из которого потом кристаллизовался магматический циркон, и изотопные характеристики этого расплава (известный параметр эпсилон $\mathrm{Hf}$ - степень отклонения изотопного отношения $\mathrm{Hf}$ в цирконе от модельного). Эти параметры не дают нам никакой информации о возрасте реальных геологических процессов, за исключением ограничения возраста магматической кристаллизации «снизу» модельным возрастом. При этом полученные изотопно-геохимические характеристики по Нf имеют смысл только в случае ненарушенности изотопной системы.

При метаморфизме в результате флюидного воздействия в породу привносится значительное количество радиогенного $\mathrm{Hf}$ и отношение ${ }^{176} \mathrm{Hf} /{ }^{177} \mathrm{Hf}$ скачкообразно увеличивается. Особенно это заметно на графике в координатах U-Pb возраст $-{ }^{176} \mathrm{Hf} /{ }^{177} \mathrm{Hf}$. Такой график для салминских эклогитов был приведен в работе [Mints et al., 2010] и повторен в рассматриваемой статье (рис. 34, а, c. 190) - практически неизменное с отметки возраста около 2.9 млрд лет ${ }^{176} \mathrm{Hf} /{ }^{177} \mathrm{Hf}$ отношение демонстрирует всплеск на отметке U-Pb возраста около 1.9 млрд лет. Интерпретация его следующая (в подписи к рис. 34, а): «около 1.9 млрд лет зафиксирована «мгновенная» добавка в цирконе радиогенного ${ }^{176} \mathrm{Hf}$, который мог высвободиться только (курсив наш) в результате перекристаллизации длительное время существовавшего архейского граната». Эта фраза очень хорошо характеризует стиль авторов «смешивать» очевидный факт (рост в цирконе радиогенного ${ }^{176} \mathrm{Hf}$ ) с ими не доказанными (возраст граната и его потенциальный вклад в «бюджет» Hf в цирконе). Где же доказательства, что возраст граната архейский? Какими изотопными методами датирования граната пользовались авторы [Mints, Dokukina, 2020], чтобы так уверенно говорить о его возрасте? Сколько в гранате находилось Hf (как элемента, так и радиогенного изотопа) до момента его «высвобождения»? Почему даже не рассматривается возможность кристаллизации граната именно во время свекофеннского метаморфизма с возрастом 1.9 млрд лет? Почему именно гранат ответственен за резкий скачок содержания радиогенного Нf в цирконе? Почему в качестве источника дополнительного количества радиогенного Hf исключается внешний флюид?

Давайте предположим (вместе с авторами [Mints, Dokukina, 2020]), что гранат все-таки кристаллизовался в архейское время. Измеренное содержание Hf в гранатах из салминских эклогитов не превышает 0.1 ppm (TIMS метод). ${ }^{176} \mathrm{Hf} /{ }^{177} \mathrm{Hf}$ отношение в нем варьируется от 0.306 до 0.317 [Herwartz et al., 2012]. Нетрудно рассчитать, с учетом природного соотношения изотопов гафния (5.3 \% для ${ }^{176} \mathrm{Hf}$ и $18.6 \%$ для $\left.{ }^{177} \mathrm{Hf}\right)$, что содержание радиогенного изотопа ${ }^{176} \mathrm{Hf}$ (возникшего путем альфа-распада из ${ }^{176} \mathrm{Lu}$ ) в гранатах не может превышать на сегодняшний день 0.0006 ppm. 1.9 млрд лет назад содержание радиогенного изотопа ${ }^{176} \mathrm{Hf}$ в гранатах было 
еще меньше и составляло не более 0.0002 ppm. Было бы ошибочным упрощением считать, что весь гафний, который присутствует в гранатах, - это продукт радиоактивного распада лютеция.

Теперь рассмотрим циркон. В каймах с возрастом около 1.9 млрд лет рост ${ }^{176} \mathrm{Hf} /{ }^{177} \mathrm{Hf}$ отношения, по сравнению с ядрами магматического генезиса, достигает 0.001 (рис. 34, а, с. 190). Содержание Hf в магматических ядрах всего лишь около 5000 ppm, а в каймах оно достигает 9000 ppm [Skublov et al., 2010, 2011]. Если рассматривать каймы циркона как частично перекристаллизованные ядра, то при этом процессе было привнесено не менее 4000 ppm Hf, что в 40000 раз (!) превышает его содержание в гранате. Эта оценка увеличится более чем вдвое, если считать каймы циркона новообразованными, без перекристаллизации ядер. Гипотетически перекристаллизация даже всего существующего в породе граната не в состоянии обеспечить такой скачок содержания гафния во флюиде. Отдельно стоит отметить, что совершенно непонятен механизм, который заставит элемент мигрировать из минерала, где содержание его крайне мало, в минерал-концентратор этого элемента. Обычно при метаморфизме в случае закрытой системы происходит выравнивание как градиентов концентраций, так и изотопных отношений (т.н. переуравновешивание изохроны). Обратный, по сути, процесс, который предлагают авторы [Mints, Dokukina, 2020], подобен осмотическому и требует серьезного обоснования и подкрепления фактическим материалом.

Также возможно оценить количество привнесенного в палеопротерозойский циркон радиогенного изотопа ${ }^{176} \mathrm{Hf}$, которое привело к увеличению ${ }^{176} \mathrm{Hf} /{ }^{177} \mathrm{Hf}$ отношения на 0.001 (рис. 34, а, с. 190). Ориентировочные расчеты показывают, что в цирконе архейского возраста содержание ${ }^{176} \mathrm{Hf}$ составляет около 260 ррm при общем содержании Hf около 5000 ppm. В цирконе палеопротерозойского возраста с общим содержанием Hf около $9000 \mathrm{ppm}$ и ${ }^{176} \mathrm{Hf} /{ }^{177} \mathrm{Hf}$ отношением около 0.282 содержание ${ }^{176} \mathrm{Hf}$ оценивается уже как $470 \mathrm{ppm}$. Прирост радиогенного изотопа ${ }^{176} \mathrm{Hf}$, даже с учетом всех возможных погрешностей, не меньше 200 ppm. Это количество в $10^{6}$ (!) раз больше, чем мог бы обеспечить гранат.

Таким образом, как на элементном, так и на изотопном уровне вклад метаморфического граната в эволюцию Hf-изотопного отношения в цирконе из эклогитов ничтожен. Доказательства архейского возраста граната из салминских эклогитов у авторов комментируемой статьи просто отсутствуют. Возвращаясь к графику в координатах U-Pb возраст $-{ }^{176} \mathrm{Hf} /{ }^{177} \mathrm{Hf}$ отношение (рис. 34, а, с. 190), дополнительно отметим, что исследователи из лаборатории GEMOC (Австралия), выполнявшие эти аналитические работы, четко выразили свою позицию по поводу как количества и возраста метаморфических событий для салминских эклогитов, так и причин увеличения ${ }^{176} \mathrm{Hf} /{ }^{177} \mathrm{Hf}$ отношения в цирконе [O’Reilly et al., 2008]. Приведем эту цитату дословно: «However, the Hf-isotope system of zircons is remarkably resistant to change, partly because zircon itself is so robust, and partly because zircon typically controls the Hf budget of the host-rock making it difficult to change the isotopic composition of a pre-existing zircon grain. Thus, zircon grains that have simply lost $\mathrm{Pb}$ during post-magmatic events will retain their Hf-isotope composition. Zircons that are newly grown during a metamorphic event will tend to incorporate more radiogenic Hf...» [O’Reilly et al., 2008, c. 985986]. В подрисуночной подписи (Там же, рис. 3, с. 986) эти же авторы объясняют разброс точек вдоль конкордии от возраста магматического протолита эклогитов до возраста палеопротерозойского метаморфизма не как следствие нескольких метаморфических событий, а как процесс потери радиогенного свинца под воздействием единственного метаморфического события свекофеннского возраста («However, the uniform Hf-isotope compositions are more consistent with non-zero Pb loss (probably at ca $1.8 \mathrm{Ga}$ ) from a ca $2.8 \mathrm{Ga}$ population, leading to spurious ${ }^{207} \mathrm{~Pb} /{ }^{206} \mathrm{~Pb}$ ages» [O'Reilly et al., 2008]). Данные об изотопном составе Hf в цирконе опровергают предположения авторов [Mints, Dokukina, 2020] об архейском возрасте эклогитового метаморфизма, никак не подкрепленные прямыми изотопно-геохимическими и геохронологическими определениями.

\section{6. ГЕОХИМИЯ ЦИРКОНА}

Авторы комментируемой статьи пытаются «датировать» эклогитовый метаморфизм с помощью спектров REE в цирконе, привязывая появление положительной Eu-аномалии, указывающей, по их мнению (с. 184), на «фракционирование плагиоклаза», к высокобарическому метаморфизму. Авторы предполагают «перекристаллизацию мафитовой магматической породы (плагиоклаз+клинопироксен) с образованием эклогитовой ассоциации «гранат+омфацит». Пористый циркон в ходе реакций растворения - переосаждения захватывает высвобождающийся Еu». Во-первых, предложенную метаморфическую реакцию исчезновения плагиоклаза фракционированием назвать никак нельзя. Фракционирование - это процесс удаления минеральной фазы из системы. Поскольку плагиоклаз обогащен $\mathrm{Eu}\left(\mathrm{Eu}^{2+}\right.$, имеющий близкий ионный радиус с $\mathrm{Sr}$, легко входит совместно с последним в кристаллическую решетку плагиоклаза по закону камуфлированного изоморфизма, замещая кальций), после его фракционирования (удаления) в системе и, соответственно, в составляющих ее минеральных фазах будет фиксироваться отрицательная Eu-аномалия, а не положительная [Schaltegger et al., 1999]. Точно такой же эффект отрицательной

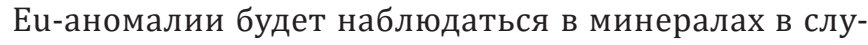
чае опережающей или одновременной кристаллизации плагиоклаза. Плагиоклаз будет «забирать» значительную часть количества Eu в породе, что приведет к появлению в сосуществующих с ним минералах, в том числе и в цирконе, отрицательной Eu-аномалии [Hoskin et al., 2000; Hoskin, Schaltegger, 2003; Bingen et al., 2004]. Нельзя исключать и ситуацию дефицита $\mathrm{Eu}$ в целом. На появление Еu-аномалии в цирконе также оказывают 
влияние окислительно-восстановительные условия. Вхождение в кристаллическую решетку циркона более крупного $\mathrm{Eu}^{2+}$ (ионный радиус $1.25 \AA$ А) затруднено по сравнению с меньшим по размерам $\mathrm{Eu}^{3+}(1.066 \AA ̊$ ), поэтому величина отрицательной Еu-аномалии зависит от $\mathrm{Eu}^{2+} / \mathrm{Eu}^{3+}$ отношения, определяемого редокс-параметрами в процессе кристаллизации [Bingen et al., 2004]. Однако $\mathrm{Eu}^{2+} / \mathrm{Eu}^{3+}$ отношение в породе в целом, количество $\mathrm{Eu}^{2+}$ или кристаллизация других фаз не являются единственными факторами, определяющими величину Eu-аномалии в цирконе [Schulz et al., 2006]. Величина отрицательной Еu-аномалии находится в сильной положительной корреляции с содержанием Ү в цирконе [Belousova et al., 2002]. Уменьшение величины отрицательной Eu-аномалии, вплоть до ее исчезновения, является характерной чертой метаморфического циркона c Th/U отношением меньше 0.01 по причине изоморфного вхождения $\mathrm{Eu}^{3+}\left(1.066 \AA\right.$ ) в позицию $\mathrm{Th}^{4+}$ (1.05 ̊) в кристаллической структуре циркона [Rubatto, 2002]. И наоборот, отрицательная Eu-аномалия в цирконе лучше проявляется в породах с высоким содержанием Тh или в случае с высокоториевым или высокоурановым цирконом из гранитоидов [Belousova et al., 2002].

Положительная Еu-аномалия менее характерна для циркона. В основном она встречается в цирконе так называемого гидротермально-метасоматического типа, кристаллизовавшегося из флюида или, что встречается реже, из флюидонасыщенного расплава. Характерной особенностью состава такого циркона является повышенное содержание LREE, приводящее к выполаживанию всего спектра REE с исчезновением или редуцированием положительной Се-аномалии, исчезновение отрицательной Еu-аномалии или смена ее знака на положительный, крайне низкое Th/U отношение, значительное количество неформульных элементовпримесей (Ca, Sr, Ba, Ti) [Levskii et al., 2009; Skublov et al., 2013b]. Внутренняя структура циркона этого типа часто характеризуется пористым строением, темной окраской в CL и BSE изображении, ростовая осцилляционная зональность в нем отсутствует. Геохимические особенности циркона гидротермально-метасоматического типа, по всей видимости, унаследованы от состава флюида. Аналогичные недифференцированные (обогащенные LREE) спектры распределения REE с положительной Eu-аномалией были установлены для современных морских гидротермальных флюидов [Bau, Dulski, 1999; Craddock et al., 2010] в современных вулканогенных гидротермальных системах [Karpov et al., 2013]. Степень положительной Еu-аномалии во многом определяется кислотно-щелочным режимом, доминирующим над окислительно-восстановительными условиями. Пористые зерна циркона, которые лежат в основе построений авторов [Mints, Dokukina, 2020], по всем признакам, как по внутреннему строению, так и по особенностям состава, относятся к гидротермальнометасоматическому типу. Положительная Eu-аномалия в них, как показано выше, унаследована от флюида и никак не может служить признаком эклогитизации базитов с исчезновением плагиоклаза.

\section{7. АЛЬТЕРНАТИВНЫЙ ПОДХОД К ДАТИРОВАНИЮ ЭКЛОГИТОВ}

\subsection{Lu-Hf и Sm-Nd системы}

Для проверки правильности вывода о свекофеннском времени эклогитового метаморфизма в БПП, установленного по цирконам с учетом их геохимических особенностей [Skublov et al., 2010, 2011, 2012], нами было проведено Lu-Hf датирование для эклогитов северо-западной части БПП (месторождение Куру-Ваара) и района с. Гридино по гранату, клинопироксену и породе в целом, результаты которого также показали возраст около 1.9 млрд лет [Herwartz et al., 2012]. Позднее было показано, что гранаты обладают проградной зональностью с пиком содержания Lu в центре зерен [Melnik, 2015; Melnik et al., 2021]. Соответственно, Lu-Hf возраст гранатов отражает время кристаллизации прежде всего центральной части зерен. При этом Sm-Nd изохронный возраст (Grt+Cpx+WR) эклогитов северо-западной части БПП также имеет значение около 1.9 млрд лет [Melnik et al., 2013]. Значение возраста гранатов по Sm-Nd изотопной системе отражает скорее возраст основного объема зерен (включая краевые части) с учетом характера зональности гранатов по Sm и Nd [Melnik, 2015; Melnik et al., 2021]. Эти данные свидетельствуют об одноактности кристаллизации гранатов и относительной кратковременности данного события. В случае гипотетической перекристаллизации гранатов проградная зональность по главным элементам и HREE, включая Lu, была бы «затерта» наложенным метаморфизмом с температурами не ниже верхов амфиболитовой фации. В случае длительного протекания свекофеннского метаморфизма с возрастом около 1.9 млрд лет, который мы рассматриваем как эклогитовый, значения возраста гранатсодержащих парагенезисов по Lu-Hf и Sm-Nd изотопным системам не совпадали бы по причине разных температур закрытия для этих систем.

Сторонники гипотезы архейского возраста беломорских эклогитов [Mints et al., 2010, 2014; Shchipansky et al., 2012; Balagansky et al., 2015] отвергают интерпретацию полученных Sm-Nd и Lu-Hf методами по Grt и Срх свекофеннских значений возраста (около 1.9 млрд лет) как возраст эклогитового метаморфизма. Значения возраста около 1.9 млрд лет, полученные этими методами, интерпретируются ими как время «перезагрузки» Sm-Nd и Lu-Hf изотопных систем при инфильтрации флюида при амфиболитовом метаморфизме на завершающем этапе Лапландско-Кольской орогении [Balagansky et al., 2015]. При этом минералы, по которым проводилось комплексное Sm-Nd и Lu-Hf датирование (Grt и Cpx), считаются полностью перекристаллизованными и по своим Sm-Nd и Lu-Hf характеристикам не отвечающими этапу эклогитового метаморфизма. Устойчивость же Lu-Hf системы подвергается сомнению из-за «неясной» температуры закрытия 
системы в гранате [Mints et al., 2014; Mints, Dokukina, 2020].

\section{2. Изотопная система кислорода}

Современными исследованиями установлено, что для циркона и граната значение $\delta^{18} 0$ является одним из самых надежных критериев, отражающих условия их генезиса, к тому же наиболее точно соответствуя изотопному составу кислорода в породе в целом [Page et al., 2014; Rubatto, Angiboust, 2015]. Для проверки равновесия зерен и оторочек циркона с возрастом 1.9 млрд лет и граната эклогитов было проведено локальное определение изотопного состава кислорода методом SIMS [Melnik et al., 2021]. Результаты исследования в минералах из будин эклогитов Куру-Ваары (с магматическим протолитом архейского возраста) показали, что изотопный состав кислорода в гранате $\left(\delta^{18} 0=4.0-\right.$ $5.0 \%$ ) находится в равновесии с составом палеопротерозойского (около 1.9 млрд лет) циркона $\left(\delta^{18} \mathrm{O}=4.5-\right.$ $5.4 \%$ ); значения же $\delta^{18} 0$ в магматических доменах циркона архейского возраста (примерно 2.88 млрд лет) значительно выше (5.1-5.9 \%о) и неравновесны с таковыми в гранате.

\section{3. Изотопно-геохимическая характеристика циркона}

Нашим коллективом при локальном датировании гетерогенного циркона из различных проявлений эклогитов БПП с одновременным изучением их геохимических особенностей «в той же точке» было установлено, что эклогитовому метаморфизму отвечает этап с возрастом около 1.9 млрд лет, ограниченный самым молодым возрастом магматического протолита эклогитов около 2.2 млрд лет и возрастом наложенных процессов 1.84-1.87 млрд лет (пегматитообразование, гранатитизация эклогитов, ретроградный амфиболитовый метаморфизм) [Skublov et al., 2010, 2011, 2012, 2013a, 2016; Berezin et al., 2012, 2013; Herwartz et al., 2012; Melnik et al., 2013; Berezin, Skublov, 2014; Melnik, 2015]. Для трех проявлений эклогитов Беломорского подвижного пояса (северо-западная часть БПП, район с. Гридино, о-ва Керетского архипелага (о-ва Сидоров и Илейки)) возраст ядер гетерогенного циркона с геохимическими особенностями типичного магматического циркона варьируется в пределах 2.9-2.4 млрд лет, а возраст метаморфических оторочек и зерен циркона с геохимическими характеристиками, указывающими на равновесие с гранатом, для всех объектов имеет значение около 1.9 млрд лет.

\section{8. ЗАКЛЮЧЕНИЕ}

Наша трактовка возраста эклогитового метаморфизма, приведшего к образованию эклогитов БПП, основанная на комплексе независимых изотопно-геохимических методов датирования - локальном U-Pb методе по гетерогенным цирконам с магматическими ядрами и эклогитовыми каймами, Lu-Hf и Sm-Nd методах по минералам эклогитового парагенезиса - гранату и омфациту, принципиально иная, чем в рассматриваемой статье: все три метода независимо друг от друга определяют эклогитовый метаморфизм как свекофеннский, с одним и тем же значением возраста - около 1.9 млрд лет.

Таким образом, по нашим данным, эклогиты Беломорского подвижного пояса являются одними из самых древних высокобарических пород с достоверно установленным возрастом метаморфизма около 1.9 млрд лет при различном возрасте магматического протолита в интервале от 2.2 до 2.9 млрд лет.

\section{9. БЛАГОДАРНОСТИ}

Авторы признательны А.Е. Мельнику за участие в исследовании эклогитов Беломорья.

\section{0. ЛИТЕРАТУРA / REFERENCES}

Balagansky V., Shchipansky A., Slabunov A., Gorbunov I., Mudruk S., Sidorov M., Azimov P., Egorova S., Stepanova A., Voloshin A., 2015. Archean Kuru-Vaara Eclogites in the Northern Belomorian Province, Fennoscandian Shield: Crustal Architecture, Timing and Tectonic Implications. International Geology Review 57 (11-12), 1543-1565. https://doi.org/ 10.1080/00206814.2014.958578.

Bau M., Dulski P., 1999. Comparing Yttrium and Rare Earths in Hydrothermal Fluids from the Mid-Atlantic Ridge: Implications for $\mathrm{Y}$ and REE Behaviour during Near-Vent Mixing and for the Y/Ho Ratio of Proterozoic Seawater. Chemical Geology 155 (1-2), 77-90. https://doi.org/10. 1016/S0009-2541(98)00142-9.

Belousova E.A., Griffin W.L., O’Reilly S.Y., Fisher N.L., 2002. Igneous Zircon: Trace Element Composition as an Indicator of Source Rock Type. Contributions to Mineralogy and Petrology 143, 602-622. https://doi.org/10.1007/s00410002-0364-7.

Berezin A.V., Skublov S.G., 2014. Eclogite-Like Apogabbro Rocks in Sidorov and Bolshaya Ileika Islands, Keret Archipelago, White Sea: Compositional Characteristics, Metamorphic Age and Conditions. Petrology 22 (3), 234-254. https://doi.org/10.1134/S0869591114030035.

Berezin A.V., Skublov S.G., Marin Y.B., Mel'nik A.E., Bogomolov E.S., 2013. New Occurrence of Eclogite in the Belomorian Mobile Belt: Geology, Metamorphic Conditions, and Isotope Age. Doklady Earth Sciences 448, 43-53. https:// doi.org/10.1134/S1028334X13010029.

Berezin A.V., Travin V.V., Marin Y.B., Skublov S.G., Bogomolov E.S., 2012. New U-Pb and Sm-Nd Ages and PT Estimates for Eclogitization in the Fe-Rich Gabbro Dyke in Gridino Area (Belomorian Mobile Belt). Doklady Earth Sciences 444, 760-765. https://doi.org/10.1134/S1028334 X12060207.

Berman R.G., 1988. Internally-Consistent Thermodynamic Data for Minerals in the System $\mathrm{Na}_{2} \mathrm{O}-\mathrm{K}_{2} \mathrm{O}-\mathrm{CaO}-\mathrm{MgO}-$ - $\mathrm{FeO}-\mathrm{Fe}_{2} \mathrm{O}_{3}-\mathrm{Al}_{2} \mathrm{O}_{3}-\mathrm{SiO}_{2}-\mathrm{TiO}_{2}-\mathrm{H}_{2} \mathrm{O}-\mathrm{CO}_{2}$. Journal of Petrology 29 (2), 445-522. https://doi.org/10.1093/petrology/ 29.2.445.

Bingen B., Austrheim H., Whitehouse M.J., Davis W.J., 2004. Trace Element Signature and U-Pb Geochronology of 
Eclogite-Facies Zircon, Bergen Arcs, Caledonides of W Norway. Contributions to Mineralogy and Petrology 147, 671-683. https://doi.org/10.1007/s00410-004-0585-z.

Craddock P.R., Bach W., Seewald J.S., Rouxel O.J., Reeves E., Tivey M.K., 2010. Rare Earth Element Abundances in Hydrothermal Fluids from the Manus Basin, Papua New Guinea: Indicators of Sub-seafloor Hydrothermal Processes in BackArc Basins. Geochimica et Cosmochimica Acta 74 (19), 54945513. https://doi.org/10.1016/j.gca.2010.07.003.

Dokukina K.A., Bayanova T.B., Kaulina T.V., Travin A.V., Mints M.V., Konilov A.N., Serov P.A., 2012. The Belomorian Eclogite Province: Sequence of Events and Age of the Igneous and Metamorphic Rocks of the Gridino Association. Russian Geology and Geophysics 53 (10), 1023-1054. https://doi. org/10.1016/j.rgg.2012.08.006.

Dokukina K.A., Kaulina T.V., Konilov A.N., Mints M.V., Wan K.V., Natapov L.M., Belousova E.A., Simakin S.G., Lepekhina E.N., 2014. The Belomorian Eclogite Province: Sequence of Events and Age of the Igneous and Metamorphic Rocks of the Gridino Association. Gondwana Research 25 (2), 585-613. https://doi.org/10.1016/j.gr.2013.02.014.

Dokukina K.A., Konilov A.N., 2011. Metamorphic Evolution of the Gridino Mafic Dyke Swarm (Belomorian Eclogite Province, Russia). In: L. Dobrzhinetskaya, S. Cuthbert, W. Faryad, S. Wallis (Eds), Ultrahigh-Pressure Metamorphism. 25 Years after the Discovery of Coesite and Diamond. Elsevier, Amsterdam, p. 579-621. https://doi.org/10.1016/ B978-0-12-385144-4.00017-5.

Dokukina K.A., Konilov A.N., Bayanova T.B., Kaulina T.V., Travin A.V., 2010. New Geochronological Data on Metamorphic and Igneous Rocks from the Gridino Village Area (Belomorian Eclogitic Province). Doklady Earth Sciences 432, 255-258. https://doi.org/10.1134/S1028334X10050260.

Dokukina K.A., Mints M.V., 2019. Subduction of the Mesoarchaean Spreading Ridge and Related Metamorphism, Magmatism and Deformation by the Example of the Gridino Eclogitized Mafic Dyke Swarm, the Belomorian Eclogite Province, Eastern Fennoscandian Shield. Journal of Geodynamics 123, 1-37. https://doi.org/10.1016/j.jog.2018.11.003.

Herwartz D., Skublov S.G., Berezin A.V., Mel'nik A.E., 2012. First Lu-Hf Garnet Ages of Eclogites from the Belomorian Mobile Belt (Baltic Shield, Russia). Doklady Earth Sciences 443, 377-380. https://doi.org/10.1134/S1028334X120 30130.

Holtz F., Johannes W., Tamic N., Behrens H., 2001. Maximum and Minimum Water Contents of Granitic Melts Generated in the Crust: A Reevaluation and Implications. Lithos 56 (1), 1-14. https://doi.org/10.1016/S0024-4937(00)0 0056-6.

Hoskin P.W., Kinny P.D., Wyborn D., Chappell B.W., 2000. Identifying Accessory Mineral Saturation during Differentiation in Granitoid Magmas: An Integrated Approach. Journal of Petrology 41 (9), 1365-1396. https://doi.org/10. 1093/petrology/41.9.1365.

Hoskin P.W.O., Schaltegger U., 2003. The Composition of Zircon and Igneous and Metamorphic Petrogenesis. Reviews in Mineralogy and Geochemistry 53, 27-62. https:// doi.org/10.2113/0530027.
Karpov G.A., Nikolaeva A.G., Alekhin Y.V., 2013. Abundances and Sources of Rare-Earth Elements in the Modern Volcanogenic Hydrothermal Systems of Kamchatka. Petrology 21 (2), 145-157. https://doi.org/10.1134/S0869591 113020045.

Kaulina T.V., Yapaskurt V.O., Presnyakov S.L., Savchenko E.E., Simakin S.G., 2010. Metamorphic Evolution of the Archean Eclogite-like Rocks of the Shirokaya and Uzkaya Salma Area (Kola Peninsula): Geochemical Features of Zircon, Composition of Inclusions, and Age. Geochemistry International 48 (9), 871-890. https://doi.org/10.1134/S00 1670291009003 X.

Konilov A.N., Shchipansky A.A., Mints M.V., Dokukina K.A., Kaulina T.V., Bayanova T.B., Natapov L.M., Belousova E.A., Griffin W.L., O'Reilly S.Y., 2011. The Salma Eclogites of the Belomorian Province, Russia: HP/UHP Metamorphism through the Subduction of Mesoarchean Oceanic Crust. In: L. Dobrzhinetskaya, S. Cuthbert, W. Faryad, S. Wallis (Eds), Ultrahigh-Pressure Metamorphism. 25 Years after the Discovery of Coesite and Diamond. Elsevier, Amsterdam, p. 623-670. https://doi.org/10.1016/B978-0-12-385144-4.00018-7.

Levskii L.K., Skublov S.G., Gembitskaya I.M., 2009. Isotopic-Geochemical Study of Zircons from Metabasites of the Kontokki Dike Complex: Age of Regional Metamorphism in the Kostomuksha Structure. Petrology 17 (7), 669-683. https://doi.org/10.1134/S0869591109070030.

Li X., Zhang L., Wei C., Slabunov A.I., Bader T., 2017. Neoarchean-Paleoproterozoic Granulite-Facies Metamorphism in Uzkaya Salma Eclogite-Bearing Mélange, Belomorian Province (Russia). Precambrian Research 294, 257-283. https://doi.org/10.1016/j.precamres.2017.03.031.

Li X., Zhang L., Wei C., Slabunov A.I., Bader T., 2018. Quartz and Orthopyroxene Exsolution Lamellae in Clinopyroxene and the Metamorphic P-T Path of Belomorian Eclogites. Journal of Metamorphic Geology 36 (1), 1-22. https://doi. org/10.1111/jmg.12280.

Melnik A.E., 2015. Eclogites from the Northwestern Part of the White Sea Mobile Belt: Geochemical Characteristics and Time of Metamorphism. PhD Thesis (Candidate of Geology and Mineralogy). Saint Petersburg, 196 p. (in Russian) [Мельник А.Е. Эклогиты северо-западной части Беломорского подвижного пояса: геохимическая характеристика и время метаморфизма: Дис. ... канд. геол.-мин. наук. СПб., 2015. 196 с.].

Melnik A.E., Skublov S.G., Marin Yu.B., Berezin A.V., Bogomolov E.S., 2013. New Data on the Age (U-Pb, Sm-Nd) of Garnetites from Salma Eclogites of the Belomorian Mobile Belt. Doklady Earth Sciences 448, 78-85. https://doi.org/ 10.1134/S1028334X13010133.

Melnik A.E., Skublov S.G., Rubatto D., Müller D., Li X.-H., Li Q.-L., Berezin A.V., Herwartz D., Machevariani M.M., 2021. Garnet and Zircon Geochronology of the Paleoproterozoic Kuru-Vaara Eclogites, Northern Belomorian Province, Fennoscandian Shield. Precambrian Research 353, 106014. https://doi.org/10.1016/j.precamres.2020.106014.

Mills K., 2011. The Estimation of Slag Properties. Short Course Presented as Part of Southern African Pyrometallurgy. Imperial College, London, $52 \mathrm{p}$. 
Mints M.V., Belousova E.A., Konilov A.N., Natapov L.M., Shchipansky A.A., Griffin W.L., O’Reilly S.Y., Dokukina K.A., Kaulina T.V., 2010. Mesoarchean Subduction Processes: 2.87 Ga Eclogites from the Kola Peninsula, Russia. Geology 38 (8), 739-742. https://doi.org/10.1130/G31219.1.

Mints M.V., Dokukina K.A., 2020. The Belomorian Eclogite Province (Eastern Fennoscandian Shield, Russia): Meso-Neoarchean or Late Paleoproterozoic? Geodynamics \& Tectonophysics 11 (1), 151-200 (in Russian) [Минц М.В., Докукина К.А., 2020. Субдукционные эклогиты Беломорской эклогитовой провинции (восток Фенноскандинавского щита, Россия): мезоархей, неоархей или поздний палеопротерозой? // Геодинамика и тектонофизика. 2020. Т. 11. № 1. С. 151-200]. https://doi.org/ 10.5800/GT-2020-11-1-0469.

Mints M.V., Dokukina K.A., Konilov A.N., 2014. The MesoNeoarchaean Belomorian Eclogite Province: Tectonic Position and Geodynamic Evolution. Gondwana Research 25 (2), 561-584. https://doi.org/10.1016/j.gr.2012.11.010.

O’Reilly S.Y., Griffin W.L., Pearson N.J., Jackson S.E., Belousova E.A., Alard O., Saeed A., 2008. Taking the Pulse of the Earth: Linking Crustal and Mantle Events. Australian Journal of Earth Sciences 55 (6-7), 983-995. https://doi.org/ $10.1080 / 08120090802097450$.

Page F.Z., Essene E.J., Mukasa S.B., Valley J.W., 2014. A Garnet-Zircon Oxygen Isotope Record of Subduction and Exhumation Fluids from the Franciscan Complex, California. Journal of Petrology 55 (1), 103-131. https://doi.org/10. 1093/petrology/egt062.

Rosen O.M., Shchipansky A.A., Turkina O.M., 2008. Geodynamics of the Early Earth: Evolution and Stability of Geological Processes (Ophiolites, Island Arcs, Cratons, and Sedimentary Basins). Nauchny Mir, Moscow, 184 p. (in Russian) [Розен О.М., Щипанский А.А., Туркина О.М. Геодинамика ранней Земли: эволюция и устойчивость геологических процессов (офиолиты, островные дуги, кратоны, осадочные бассейны). М.: Научный мир, 2008. 184 с.].

Rubatto D., 2002. Zircon Trace Element Geochemistry: Partitioning with Garnet and the Link between U-Pb Ages and Metamorphism. Chemical Geology 184 (1-2), 123-138. https://doi.org/10.1016/S0009-2541(01)00355-2.

Rubatto D., Angiboust S., 2015. Oxygen Isotope Record of Oceanic and High-Pressure Metasomatism: A P-T-TimeFluid Path for the Monviso Eclogites (Italy). Contributions to Mineralogy and Petrology 170, 44. https://doi.org/10. 1007/s00410-015-1198-4.

Sanditov D.S., 2016. On the Nature of the Liquid-to-Glass Transition Equation. Journal of Experimental and Theoretical Physics 123 (3), 429-442. https://doi.org/10.1134/ S1063776116070219.

Schaltegger U., Fanning C.M., Günther D., Maurin J.C., Schulmann K., Gebauer D., 1999. Growth, Annealing and Recrystallization of Zircon and Preservation of Monazite in High-Grade Metamorphism: Conventional and in-Situ U-Pb Isotope, Cathodoluminescence and Microchemical Evidence. Contributions to Mineralogy and Petrology 134, 186-201. https://doi.org/10.1007/s004100050478.
Schiffman P., Liou J.G., 1980. Synthesis and Stability Relations of Mg-Al Pumpellyite, $\mathrm{Ca}_{4} \mathrm{Al}_{5} \mathrm{MgSi}_{6} \mathrm{O}_{21}(\mathrm{OH})_{7}$. Journal of Petrology 21 (3), 441-474. https://doi.org/10.1093/ petrology/21.3.441.

Schulz B., Klemd R., Brätz, H., 2006. Host Rock Compositional Controls on Zircon Trace Element Signatures in Metabasites from the Austroalpine Basement. Geochimica et Cosmochimica Acta 70 (3), 697-710. https: //doi.org/10. 1016/j.gca.2005.10.001.

Shchipansky A.A., Khodorevskaya L.I., Slabunov A.I., 2012. The Geochemistry and Isotopic Age of Eclogites from the Belomorian Belt (Kola Peninsula): Evidence for Subducted Archean Oceanic Crust. Russian Geology and Geophysics 53 (3), 262-280. https://doi.org/10.1016/j.rgg.2012. 02.004 .

Silver L., Stolper E., 1985. A Thermodynamic Model for Hydrous Silicate Melts. The Journal of Geology 93 (2), 161177. https://doi.org/10.1086/628938.

Skublov S.G., Balashov Yu.A., Marin Yu.B., Berezin A.V., Mel'nik A.E., Paderin I.P., 2010. U-Pb Age and Geochemistry of Zircons from Salma Eclogites (Kuru-Vaara Deposit, Belomorian Belt). Doklady Earth Sciences 432, 791-798. https://doi.org/10.1134/S1028334X10060188.

Skublov S.G., Berezin A.V., Berezhnaya N.G., 2012. General Relations in the Trace-Element Composition of Zircons from Eclogites with Implications for the Age of Eclogites in the Belomorian Mobile Belt. Petrology 20 (5), 427-449. https://doi.org/10.1134/S0869591112050062.

Skublov S.G., Berezin A.V., Mel'nik A.E., 2011. Paleoproterozoic Eclogites in the Salma Area, Northwestern Belomorian Mobile Belt: Composition and Isotopic Geochronologic Characteristics of Minerals and Metamorphic Age. Petrology 19 (5), 470-495. https://doi.org/10.1134/S086 9591111050055.

Skublov S.G., Berezin A.V., Melnik A.E., Astafiev B.Y., Voinova O.A., Alekseev V.I., 2016. Protolith Age of Eclogites from the Southern Part of Pezhostrov Island, Belomorian Belt: Protolith of Metabasites as Indicator of Eclogitization Time. Petrology 24 (6), 594-607. https://doi.org/10.1134/S086 9591116040056.

Skublov S.G., Mel'nik A.E., Berezin A.V., Bogomolov E.S., Marin Yu.B., Ishmurzin F.I., 2013a. New Data on the Age (U-Pb, Sm-Nd) of Metamorphism and a Protolith of Eclogite-Like Rocks from the Krasnaya Guba Area, Belomorian Belt. Doklady Earth Sciences 453, 1158-1164. https://doi.org/10. 1134/S1028334X13110184.

Skublov S.G., Myskova T.A., Marin Yu.B., Astaf'ev B.Yu., Bogomolov E.S., L'vov P.A., 2013b. Geochemistry of Zircon Rims with Different Ages in Gneisses of the Kola Series (SIMS, SHRIMP-II) and the Problem of Early Caledonian Thermal Activization of the Kola Craton. Doklady Earth Sciences 453, 1250-1256. https://doi.org/10.1134/S1028334X13 120167.

Zanotto E.D., Cassar D.R., 2017. The Microscopic Origin of the Extreme Glass-Forming Ability of Albite and $\mathrm{B}_{2} \mathrm{O}_{3}$. Scientific Reports 7 (1), 1-13. https://doi.org/10.1038/ srep43022. 